\title{
Contract Manufacturer's Encroachment Strategy Considering Advertising Effort
}

\author{
Jing Shi \\ School of Economics \& Management, Shanghai Maritime University, Shanghai, China \\ Email: jingshi@shmtu.edu.cn
}

How to cite this paper: Shi, J. (2020). Contract Manufacturer's Encroachment Strategy Considering Advertising Effort. Journal of Service Science and Management, 13, 229-243. https://doi.org/10.4236/jssm.2020.132015

Received: February 13, 2020

Accepted: March 31, 2020

Published: April 3, 2020

Copyright $\odot 2020$ by author(s) and Scientific Research Publishing Inc. This work is licensed under the Creative Commons Attribution International License (CC BY 4.0).

http://creativecommons.org/licenses/by/4.0/ (c) (i) Open Access

\begin{abstract}
This paper investigates a vertical supply chain consisting of an original equipment manufacturer (OEM) and a contract manufacturer, who performs production function for the OEM. The contract manufacturer decides whether to encroach the OEM's market and build her own private brand. The advertising effort of two members is considered. The results show that the contract manufacturer's encroachment decreases the profit margin of the OEM and increases the wholesale price. When the substitution effect is sufficiently small, the introduction of the private brand slightly harms the benefit of the OEM. However, when the substitution effect is sufficiently large, the introduction of the private brand can significantly benefit the OEM which is counterintuitive. The introduction of the private brand is beneficial for the contract manufacturer and the whole supply chain. The management insight is that: For the contract manufacturer, it is better to introduce a highly substitutable brand with the OEM, which can significantly benefit both the contract manufacturer and the OEM.
\end{abstract}

\section{Keywords}

Supply Chain, Contract Manufacturer, OEM, Encroachment, Private Brand, Game Theory, Advertising Effort

\section{Introduction}

It is common that original equipment manufacturers (OEMs) outsource production to contract manufacturers (CMs) (Niu et al., 2015; Chen et al., 2012; Kaya, 2011; Zhang, 2011). For example, Apple is an OEM and operates a well-known brand "Apple". Apple purchases component from Samsung Electronics Co., Ltd. Foxconn provides assembly service for Apple. Both are contract manufacturers of Apple. In recent years, more and more contract manufacturers start to build 
their own brands. This activity is called encroachment (Cui, 2019; Chen et al., 2019; Yu \& Zheng, 2019; Zhang et al., 2018). For example, Samsung Electronics Co., Ltd. has its own cellphone brand Galaxy selling in the end consumer market and competing with iPhone (Cui, 2019). https://www.biyao.com is a newly built e-commerce platform in China and has developed fast in recent years. This platform provides the opportunities for the contract manufacturer to build their own brands. This platform gathers many contract manufacturers of well-known OEM's brands, such as Channel, Dior, Prada, GUCCI, Armani, MUJI, Nike and Adidas, etc.

Many contract manufacturers on that platform try to build their own brands for the first time. They can communicate with consumers directly. The contract manufacturers in that platform describe themselves as "The manufacturer/or supplier of (the name of the OEM)". For one thing, this declaration makes them believable that the quality of the product is as good as the OEM's brands. The OEM's brands are usually well-known in the market. This tactic will attract the attention of consumers for the private brand. For another thing, this declaration also has positive effect on the OEM's brand, because this kind of declaration will make more people know about the OEM's brand and make the OEM's brand more valuable. As a result, the advertising effort of the contract manufacturer's private brand will positively impact both itself and the OEM. Similarly, the advertising effort of the OEM's brand will also positively impact the OEM's brand and the contract manufacturer's private brand. This paper builds game models to capture this phenomenon. For the contract manufacturer, she has two different kinds of strategies to choose from: not introducing a private brand (NPB) or introducing a private brand ( $\mathrm{PB})$. Some interesting questions arise as follows.

1) What are the optimal decisions of supply chain members under two different private brand strategies?

2) What are the effects of the contract manufacturer's encroachment on the OEM, contract manufacturer and the whole supply chain?

3) Is it always bad for the OEM to let the contract manufacturer introduce a private brand?

4) What should the contract manufacturer do if she has already decided to introduce a private brand?

To answer these questions, this paper builds two game models under strategy PB and strategy NPB. Then the decisions and profits under two strategies are compared to investigate the effect of the contract manufacturer's encroachment.

This paper contributes to literature in following ways: Firstly, to the author's best knowledge, there is no paper considered the contract manufacturer's establishment of private brand considering advertising effort. This paper fills the gap. Secondly, this paper finds some counterintuitive results which are interesting. When the substitution effect is sufficiently small, the introduction of the private brand slightly harms the benefit of the OEM. However, when the substitution effect is sufficiently large, the introduction of the private brand can significantly benefit the OEM which is counterintuitive. Third, this paper provides some 
suggestions for practice to help contract manufacturer build a private brand. For the contract manufacturer, it is better to introduce a highly substitutable brand with the OEM, which can significantly benefit both the contract manufacturer and the OEM.

\section{Literature Review}

This paper relates to contract manufacturer's encroachment and advertising effort. This part will review related literature.

\subsection{Contract Manufacturer's Encroachment}

Recently more and more contract manufacturers start to introduce their own brands. There are mainly two streams of literature. The first stream states that encroachment is not beneficial for the contract manufacturer. Spiegel (1993) states horizontal contract manufacturers have no incentive to build their own brand. Lim and Tan (2010) jointly study the impact of rate of learning and the brand equity on the supplier's entry strategy. There results show that when the buyer's rate of learning is moderate or low, the supplier always encroaches to compete directly with the buyer. However, if the buyer has a high brand equity, the negative effect of the supplier's entry can be mitigated. However, this horizontal is based on symmetric cost.

The second stream finds the condition under which it is beneficial for the contract manufacturer to encroach. Cui (2019) studies a supply chain encroachment where the potential market entrant contract manufacturer is a free rider who can imitate the OEM's product quality. They find that when there is no quality investment opportunity, the CM always has the incentive to encroach. However, if the OEM can improve quality, there exists a threshold for the CM's imitating capability. Shi (2019) studies the contract manufacture's encroachment strategy considering quality investment under OEM-Stackelberg setting and contract manufacturer-Stackelberg setting, respectively. Different to Cui (2019) and Shi (2019), this paper studies the contract manufacturer's encroachment strategy considering advertising effort, especially the advertising effort of OEM and contract manufacturer have cross positive effect on each other. Chen et al. (2019) study a supply chain consisting of a CM, an OEM, and a retailer. The OEM designs a national brand and outsources the manufacturing to the CM and delegates the selling to the retailer. They find that all supply-chain players benefit from factory encroachment provided there is no integration between the OEM and the retailer. However, if the OEM and the retailer are independent entities, all members prefer no-encroachment strategy. Similarly, this paper also finds the impact of contract manufacture's encroachment on supply chain members. When the substitution effect is sufficiently small, the introduction of the private brand slightly harms the benefit of the OEM. However, when the substitution effect is sufficiently large, the introduction of the private brand can significantly benefit the OEM. The contract manufacturer and the whole supply chain always prefer encroachment. 


\subsection{Advertising Effort}

Advertising effort also has been extensively studied. One stream of the literature studies the impact of advertising effort on the demand. They believe that the advertising effort plays a significant role in promoting brand goodwill and in turn has a positive effect on the demand (Zhang, Gou, Liang, \& Huang, 2013; Ouardighi \& Kogan, 2013). Song et al. (2017) integrates firms' innovation and advertising decisions in a two-echelon supply chain. Both innovation and advertising contribute to the product demand. Another stream of the literature studies cooperative advertising which is arranged between one manufacturer and one retailer, where the retailer is responsible for local advertising expense with a part of the cost undertaken by the manufacturer (Wang, Zhou, Min, \& Zhong, 2011). Readers can refer to Aust and Buscher (2014) for a comprehensive review in cooperative advertising. Some people study the impact of local advertising effort on the demand. Berger (1972) was probably the first to analyze cooperative advertising issues between a manufacturer and a retailer quantitatively. Then this issue was extensively studied (Berger, 1973; Berger \& Magliozzi, 1992; Dutta, Bergen, John \& Rao, 1995; Fulop, 1988; Somers, Gupta, \& Herriott, 1990; Young \& Greyser, 1983). Some scholars study the manufacturer's advertising on national brand name. Li et al. (2002) take the advertising effort on national brand name into the cooperative advertising model for a one-manufacturer-one-retailer supply chain. Chaab and Rasti-Barzoki (2016) studies the cooperative advertising and pricing in the Nash, Stackelberg retailer, Stackelberg manufacturer and cooperation games. Different to above literature, this paper studies the effect of the introduction of the OEM manufacturer's private brand. The OEM and the contract manufacturer invest on their own brand and they do not cooperative on advertising. However, because there is a positive effect of the advertising effort on the other brand, introducing a private brand by the OEM manufacturer can also benefit the OEM's brand which has the same effect with cooperative advertising.

\subsection{Research Gap}

This research has several substantial differences with existing literature. First, this paper combines advertising effort with contract manufacturer's encroachment strategy for the first time. Second, different to dual-channel's cooperative advertising, this paper assumes that there are two different brands. Each of them has a certain level of advertising effort. Third, this paper finds some counterintuitive results which complement existing literature. When the substitution effect is sufficiently small, the introduction of the private brand slightly harms the benefit of the OEM. However, when the substitution effect is sufficiently large, the introduction of the private brand can significantly benefit the OEM.

\section{Basic Model}

This paper studies a supply chain consisting of a contract manufacturer and an 
OEM (original equipment manufacturer). The contract manufacturer produces product for the OEM who sells to consumers. The OEM has a higher market power and acts as a leader in the supply chain. Advertising effort is an important factor influencing market demand and the OEM usually spends significant amount of expenditure on advertising to attract consumers.

Recently, more and more contract manufacturers start to introduce their own private brands or factory brand (Chen et al., 2019), i.e., the contract manufacturers produce products and label them under their own brand names. Thus, the contract manufacturer has two strategies: PB (building a private brand) or NPB (not building a private brand). Under strategy $\mathrm{PB}$, the contract manufacturer needs to decides the advertising effort $s_{d}$ and the retail price of the private brand $p_{d}$.

The advertising effort of both members aim at stimulating sales of their products in the market. There are all kinds of advertisement in the market. For example, TV, newspaper, magazine, contests, elevator advertisement, outdoor advertisement, online ads, implanted advertisement etc. (Kalra \& Shi, 2010; Karray \& Martín-Herrán, 2019). Hereafter, "she" denotes the contract manufacturer and "he" denotes the OEM.

\subsection{Basic Model under Strategy PB}

Under strategy $\mathrm{PB}$, both the OEM's brand and contract manufacturer's private brand exist in the market. Because the contract manufacturer will take advantages of her present technology and capacity, this paper assumes that the private brand produces substitutable products with the OEM' brand. To characterize each brand's demand function, this paper adopts a utility function of a representative consumer introduced by Ingene \& Parry (2004), which has been applied extensively in the field of marketing and operations management (Cai, 2010; Chen et al., 2017). Based on the literature, the representative consumer's utility is

$$
U=a D+a_{d} D_{d}-D^{2} / 2-D_{d}^{2} / 2-\theta D D_{d}-p D-p_{d} D_{d}
$$

By maximization of the representative consumer surplus, the demand of the OEM' brand and the contract manufacturer's private brand are

$$
\begin{aligned}
& D^{P B}=\left(a-\theta a_{d}-p+\theta p_{d}\right) /\left(1-\theta^{2}\right) \\
& D_{d}^{P B}=\left(a_{d}-\theta a-p_{d}+\theta p\right) /\left(1-\theta^{2}\right)
\end{aligned}
$$

where $a=a_{0}+\alpha s+\beta s_{d} ; \quad a_{d}=a_{d 0}+\alpha s_{d}+\beta s$.

The expression $a=a_{0}+\alpha s+\beta s_{d}$ and $a_{d}=a_{d 0}+\alpha s_{d}+\beta s$ represent the expanded base demand of the OEM's brand and the contract manufacturer's private brand. $a_{0}$ and $a_{d 0}$ are the baseline demand of each brand when they are not advertised. The baseline demand of each brand is increased by the advertising effort. The sensitivity of one brand's demand on its own advertising effort is $\alpha$ and the sensitivity of one brand's demand on another brand's advertising effort is $\beta$. This assumption is derived from practice. For example, biyao.com 
gathers a lot of contract manufacturers of well-known OEM brands, such as Nike, Adidas, Coach, Prada, etc. Those contract manufacturers label "the supplier of (the name of the OEM's brand)" on the product page. Thus, when the OEM advertises, more people will know about the OEM's brand. However, part of it may seek to buy similar product from the contract manufacturer. When the contract manufacturer advertises with the label "The supplier of (the name of the OEM's brand)", more people will know about the OEM's brand as well. The advertising on one brand has a positive effect on the other brand but this indirect effect maybe weaker than the direct effect, i.e. $\beta<\alpha$.

Brand substitution is represented by the positive parameter $\theta \in(0,1)$. When $\theta=0$, the brands are purely monopolistic; as $\theta$ approaches 1 , the brands converge to purely substitutable. The production costs of both brands are equal since the contract manufacturer produces two substitutable products (Spiegel, 1993; Niu et al., 2015). By maximizing the representative consumer's utility function, the demand functions can be derived as follow.

The demand of the OEM's brand is

$$
D^{P B}=\left[\left(a_{0}-a_{d 0} \theta\right)+s(\alpha-\beta \theta)+s_{d}(\beta-\alpha \theta)-p+p_{d} \theta\right] /\left(1-\theta^{2}\right)
$$

The demand of the contract manufacturer's private brand is

$$
D_{d}^{P B}=\left[\left(a_{d 0}-a_{0} \theta\right)+s_{d}(\alpha-\beta \theta)+s(\beta-\alpha \theta)-p_{d}+p \theta\right] /\left(1-\theta^{2}\right)
$$

The profit of the OEM under strategy $\mathrm{PB}$ is

$$
\pi_{R}^{P B}=m D^{P B}-\eta s^{2} / 2
$$

The profit of the contract manufacturer under strategy $\mathrm{PB}$ is

$$
\pi_{M}^{P B}=(w-c) D^{P B}+\left(p_{d}-c\right) D_{d}^{P B}-\eta s_{d}^{2} / 2
$$

Above formulations assume that the advertising costs of both the OEM and the contract manufacturer are quadratic to represent increasing marginal costs of advertising which is commonly seen in literature (De Giovanni, 2011; Zhang, et al., 2013; Chen, et al., 2017; Xiao, et al., 2020).

The time sequence is as follows. The OEM determines the profit margin $m$ and advertising effort $s$ simultaneously. The contract manufacturer determines the wholesale price $w$, advertising effort $s_{d}$ and retail price of the private brand $p_{d}$. This time sequence is not uncommon in practice. Many OEM such as Nike and Adidas have higher market power in the value chain than the contract manufacturer and can move first as a leader (Edirisinghe \& Shi, 2011; Pan, et al., 2010). The contract manufacturer usually acts as a follower.

\subsection{Basic Model under Strategy NPB}

Under strategy NPB, the contract manufacturer determines not to introduce a private brand and concentrates on producing product for the OEM. Since $D_{d}=0$, Equation (1) can be simplified as follows.

$$
U^{N P B}=a D-D^{2} / 2-p D
$$


By maximization of the representative consumer surplus, $D^{N P B}=a-p$ can be obtained, where $a=a_{0}+\alpha s$. Then the final demand function of the OEM is as follows.

$$
D^{N P B}=a_{0}-p+\alpha s
$$

Under strategy NPB, the profit of the OEM is

$$
\pi_{R}^{N P B}=m D^{N P B}-\eta s^{2} / 2
$$

Under strategy NPB, the profit of the contract manufacturer is

$$
\pi_{M}^{N P B}=(w-c) D^{N P B}
$$

\section{Equilibrium Analysis}

\subsection{Equilibrium Analysis under Strategy PB}

In this section, Backward induction is used to solve the game under strategy PB. Proposition 1 is derived as follows.

Proposition 1. Under strategy $\mathrm{PB}$, if $\eta>\max \left\{\alpha^{2}+\beta^{2}-2 \alpha \beta \theta /\left[2\left(1-\theta^{2}\right)\right], \alpha^{2} / 2\right\}$ and $T<0$, the equilibrium results are as follows. The optimal profit margin and advertising effort of the OEM are $m^{P B *}=\left\{2 \eta\left[K-a_{0}\left(\alpha^{2}-2 \eta\right)\right]\left[\alpha^{2}+\beta^{2}-2 \alpha \beta \theta-2 \eta\left(1-\theta^{2}\right)\right]\right\} / T$ and $s^{P B *}=\left\{\left[\alpha^{3}-\alpha\left(\beta^{2}+2 \eta\right)+2 \beta \eta \theta\right]\left[K-a_{0}\left(\alpha^{2}-2 \eta\right)\right]\right\} / T$, respectively. The wholesale price, retailer price and the advertising effort of the contract manufacturer are $w\left(m^{P B *}, s^{P B *}\right), \quad p_{d}\left(m^{P B *}, s^{P B *}\right)$ and $s_{d}\left(m^{P B *}, s^{P B *}\right)$, respectively,

Where

$$
\begin{gathered}
w(m, s)=\left\{a_{0}+c-m+s \alpha+\beta A /\left[\alpha^{2}+\beta^{2}-2 \alpha \beta \theta-2 \eta\left(1-\theta^{2}\right)\right]\right\} / 2, \\
p_{d}(m, s)=\left\{a_{d 0}+c+s \beta+\alpha A /\left[\alpha^{2}+\beta^{2}-2 \alpha \beta \theta-2 \eta\left(1-\theta^{2}\right)\right]\right\} / 2, \\
s_{d}(m, s)=A /\left[\alpha^{2}+\beta^{2}-2 \alpha \beta \theta-2 \eta\left(1-\theta^{2}\right)\right] \\
A=\left(m-a_{0}-2 s \alpha\right) \beta+c(\alpha+\beta)(1-\theta) \\
+\left[\alpha\left(a_{0}-m+s \alpha\right)+s \beta^{2}\right] \theta+a_{d 0}(\beta \theta-\alpha) \\
K=c[\alpha(\alpha-\beta)-2 \eta(1-\theta)]+a_{d 0}(\alpha \beta-2 \eta \theta)
\end{gathered}
$$

and

$$
\begin{aligned}
T= & \alpha^{6}-2 \alpha^{4}\left(\beta^{2}+4 \eta\right)+12 \alpha^{3} \beta \eta \theta-4 \alpha \beta \eta\left(\beta^{2}+6 \eta\right) \theta \\
& +\alpha^{2}\left[\beta^{4}+4 \eta^{2}\left(5-2 \theta^{2}\right)\right]+4 \eta^{2}\left[\beta^{2}\left(2+\theta^{2}\right)-4 \eta\left(1-\theta^{2}\right)\right] .
\end{aligned}
$$

Proof: It's a two-stage game. Backward induction is used to solve this game. We start by stage 2 . The contract manufacturer's problem in stage 2 is given by

$$
\max \pi_{M}^{P B}\left(w, p_{d}, s_{d}\right)=(w-c) D^{P B}+\left(p_{d}-c\right) D_{d}^{P B}-\eta s_{d}^{2} / 2
$$

where $D^{P B}$ is given by (4) and $D_{d}^{P B}$ is given by (5).

The Hessian matrix of $\pi_{M}^{P B}$ over $\left(w, p_{d}, s_{d}\right)$ is 


$$
\begin{aligned}
& \boldsymbol{H}=\left[\begin{array}{ccc}
-2 /\left(1-\theta^{2}\right) & 2 \theta /\left(1-\theta^{2}\right) & (\beta-\alpha \theta) /\left(1-\theta^{2}\right) \\
2 \theta /\left(1-\theta^{2}\right) & -2 /\left(1-\theta^{2}\right) & (\alpha-\beta \theta) /\left(1-\theta^{2}\right) \\
(\beta-\alpha \theta) /\left(1-\theta^{2}\right) & (\alpha-\beta \theta) /\left(1-\theta^{2}\right) & -\eta
\end{array}\right] \\
& \text { Because }-2 /\left(1-\theta^{2}\right)<0,\left|\begin{array}{cc}
-\frac{2}{1-\theta^{2}} & \frac{2 \theta}{1-\theta^{2}} \\
\frac{2 \theta}{1-\theta^{2}} & -\frac{2}{1-\theta^{2}}
\end{array}\right|=\frac{4}{1-\theta^{2}}>0 \text {, and } \\
& |\boldsymbol{H}|=2\left[\alpha^{2}+\beta^{2}-2 \alpha \beta \theta-2 \eta\left(1-\theta^{2}\right)\right] /\left(1-\theta^{2}\right)^{2} \text {, as long as }|\boldsymbol{H}|<0, \pi_{M}^{P B} \text { is a } \\
& \text { concave function of }\left(w, p_{d}, s_{d}\right) \text {, i.e. } \eta>\left(\alpha^{2}+\beta^{2}-2 \alpha \beta \theta\right) /\left[2\left(1-\theta^{2}\right)\right] \text {. } \\
& w(m, s)=\left\{a_{0}+c-m+s \alpha+\beta A /\left[\alpha^{2}+\beta^{2}-2 \alpha \beta \theta-2 \eta\left(1-\theta^{2}\right)\right]\right\} / 2, \\
& p_{d}(m, s)=\left\{a_{d 0}+c+s \beta+\alpha A /\left[\alpha^{2}+\beta^{2}-2 \alpha \beta \theta-2 \eta\left(1-\theta^{2}\right)\right]\right\} / 2, \\
& s_{d}(m, s)=A /\left[\alpha^{2}+\beta^{2}-2 \alpha \beta \theta-2 \eta\left(1-\theta^{2}\right)\right],
\end{aligned}
$$

where

$$
\begin{aligned}
A= & \left(m-a_{0}-2 s \alpha\right) \beta+c(\alpha+\beta)(1-\theta) \\
& +\left[\alpha\left(a_{0}-m+s \alpha\right)+s \beta^{2}\right] \theta+a_{d 0}(\beta \theta-\alpha) .
\end{aligned}
$$

Inserting $w(m, s), p_{d}(m, s)$ and $s_{d}(m, s)$ into the OEM's profit function, the problem of the OEM can be derived as

$$
\max _{m, s} \pi_{R}^{P B}(m, s)=m D^{P B}-\eta s^{2} / 2 .
$$

We can derive

$$
\partial^{2} \pi_{R}^{P B}(m, s) / \partial m^{2}=\left(2 \eta-\alpha^{2}\right) /\left[\alpha^{2}+\beta^{2}-2 \alpha \beta \theta-2 \eta\left(1-\theta^{2}\right)\right]
$$

and

$$
\begin{aligned}
& \frac{\partial^{2} \pi_{R}^{P B}(m, s)}{\partial m^{2}} \cdot \frac{\partial^{2} \pi_{R}^{P B}(m, s)}{\partial s^{2}}-\left(\frac{\partial \pi_{R}^{P B}(m, s)}{\partial m \partial s}\right)^{2} \\
& =-\frac{T}{4\left[\alpha^{2}+\beta^{2}-2 \alpha \beta \theta-2 \eta\left(1-\theta^{2}\right)\right]^{2}},
\end{aligned}
$$

where

$$
\begin{aligned}
T= & \alpha^{6}-2 \alpha^{4}\left(\beta^{2}+4 \eta\right)+12 \alpha^{3} \beta \eta \theta-4 \alpha \beta \eta\left(\beta^{2}+6 \eta\right) \theta \\
& +\alpha^{2}\left[\beta^{4}+4 \eta^{2}\left(5-2 \theta^{2}\right)\right]+4 \eta^{2}\left[\beta^{2}\left(2+\theta^{2}\right)-4 \eta\left(1-\theta^{2}\right)\right] .
\end{aligned}
$$

Because $\alpha^{2}+\beta^{2}-2 \alpha \beta \theta-2 \eta\left(1-\theta^{2}\right)<0$, thus, if $\eta>\alpha^{2} / 2$, and $T<0$, $\pi_{R}^{P B}(m, s)$ is a concave function over $(m, s)$. By solving the first-order condition, we can get the optimal decisions of the OEM as follows.

$$
m^{P B *}=2 \eta K\left[\alpha^{2}+\beta^{2}-2 \alpha \beta \theta-2 \eta\left(1-\theta^{2}\right)\right] / T
$$




$$
s^{P B *}=\left[\alpha^{3}-\alpha\left(\beta^{2}+2 \eta\right)+2 \beta \eta \theta\right] K / T
$$

where $K=c[\alpha(\alpha-\beta)-2 \eta(1-\theta)]+a_{d 0}(\alpha \beta-2 \eta \theta)-a_{0}\left(\alpha^{2}-2 \eta\right)$.

Finally, the optimal decisions of the contract manufacturer can be obtained.

In conclusion, $\eta>\max \left\{\alpha^{2}+\beta^{2}-2 \alpha \beta \theta /\left[2\left(1-\theta^{2}\right)\right], \alpha^{2} / 2\right\}$ and $T<0$ are conditions ensuring concavity and positivity of the equilibrium.

Proposition 1 gives the equilibrium of the game under strategy $\mathrm{PB}$. The condition $\eta>\max \left\{\alpha^{2}+\beta^{2}-2 \alpha \beta \theta /\left[2\left(1-\theta^{2}\right)\right], \alpha^{2} / 2\right\}$ and $T<0$ ensures the concavity and positivity of the solution. Note that $T$ has no specific meaning, which are just used to denote a complex equation.

\subsection{Equilibrium Analysis under Strategy NPB}

By using backward induction, the equilibrium decisions under strategy NPB can be derived as follows.

Proposition 2. Under strategy NPB, if $\eta>\alpha^{2} / 4$ and $a_{0}>c$, the profit margin and advertising effort of the OEM are $m^{N P B *}=2 \eta\left(a_{0}-c\right) /\left(4 \eta-\alpha^{2}\right)$ and $s^{N P B *}=\alpha\left(a_{0}-c\right) /\left(4 \eta-\alpha^{2}\right)$, respectively. The wholesale price of the contract manufacturer is $w^{N P B *}=\left[\left(a_{0}+3 c\right) \eta-c \alpha^{2}\right] /\left(4 \eta-\alpha^{2}\right)$. The profits of the OEM and the contract manufacturer are $\pi_{R}^{N P B^{*}}=\eta\left(a_{0}-c\right)^{2} /\left[2\left(4 \eta-\alpha^{2}\right)\right]$ and $\pi_{M}^{N P B *}=\left[\eta\left(a_{0}-c\right) /\left(4 \eta-\alpha^{2}\right)\right]^{2}$, respectively.

Proof: It's a two-stage game. Firstly, we consider the contract manufacturer's problem in the second stage given by

$$
\max _{w} \pi_{M}^{N P B}=(w-c) D^{N P B}
$$

where $D^{N P B}$ is given by Equation (10).

Because $\mathrm{d}^{2} \pi_{M}^{N P B} / \mathrm{d} w^{2}=-2<0, \pi_{m}^{N P B}$ is a concave function of $w$. By solving the first-order condition, the optimal reaction function of the contract manufacturer is

$$
w(m, s)=\left(a_{0}+c-m+s \alpha\right) / 2
$$

Inserting $w(m, s)$ into the OEM's profit function, the OEM's problem is derived as

$$
\max _{m, s} \pi_{R}^{N P B}(m, s)=m D^{N P B}-\eta s^{2} / 2
$$

Because $\partial^{2} \pi_{R}^{N P B}(m, s) / \partial m^{2}=-1<0$, and

$\frac{\partial^{2} \pi_{R}^{N P B}(m, s)}{\partial m^{2}} \cdot \frac{\partial^{2} \pi_{R}^{N P B}(m, s)}{\partial s^{2}}-\left(\frac{\partial^{2} \pi_{R}^{N P B}(m, s)}{\partial m \partial s}\right)^{2}=\eta-\alpha^{2} / 4, \pi_{R}^{N P B}(s)$ is a concave function over $(m, s)$ iff $\eta>\alpha^{2} / 4$.

By solving the first-order conditions as follows, the optimal decisions of the OEM can be derived. The optimal profit margin and the optimal advertising of the OEM are derived as follows. $m^{N P B *}=\left[2 \eta\left(a_{0}-c\right)\right] /\left(4 \eta-\alpha^{2}\right)$, $s^{N P B *}=\left[\alpha\left(a_{0}-c\right)\right] /\left(4 \eta-\alpha^{2}\right)$.

Inserting $m^{N P B^{*}}$ and $s^{N P B^{*}}$ into $w(s)=\left(a_{0}+c-m+s \alpha\right) / 2$, the optimal 
wholesale price of the contract manufacturer can be derived as $w^{N P B *}=\left[\left(a_{0}+3 c\right) \eta-c \alpha^{2}\right] /\left(4 \eta-\alpha^{2}\right)$.

$\eta>\alpha^{2} / 4$ is the condition ensuring concavity, and $a_{0}>c$ ensures positive profit margin and advertising effort.

In Proposition 2, the condition $\eta>\alpha^{2} / 4$ ensures the concavity of the problem. The condition $a_{0}>c$ ensures the positivity of the results. The profit margin increases with the baseline demand and the sensitivity of one brand's demand on its own advertising effort, and decreases with the production cost. Because $\partial m^{N P B *} / \partial \eta=-2\left(a_{0}-c\right) \alpha^{2} /\left[\left(\alpha^{2}-4 \eta\right)^{2}\right]<0$, the profit margin decreases with the coefficient of advertising effort cost $\eta$. The advertising effort of the OEM increases with the baseline demand $a_{0}$ and decreases with the production cost $c$ and the coefficient of advertising effort cost $\eta$. Because $\partial s^{N P B^{*}} / \partial \alpha=\left(a_{0}-c\right)\left(\alpha^{2}+4 \eta\right) /\left[\left(\alpha^{2}-4 \eta\right)^{2}\right]>0$, the advertising effort of the OEM increases with the sensitivity of one brand's demand on its own advertising effort $\alpha$.

The management insight here is that the cost has a negative effect on profit margin and the advertising effort, whereas the baseline demand and the sensitivity of one brand's demand on its own advertising effort has a positive effect.

\subsection{The Encroachment Strategy of the Contract Manufacturer}

Because the analytic results under strategy $\mathrm{PB}$ are complicated, it is impossible to compare the results under strategy $\mathrm{PB}$ and strategy NPB directly. Thus, numerical examples are used in this section to illustrate the results. The default values of parameters are $a_{0}=100 ; a_{d 0}=50 ; \beta=0.1 ; \eta=40 ; c=30 ; \alpha=0.6$. The values of parameters ensure that the concavity and positivity conditions are all satisfied. Then following figures are obtained.

From Figure 1, the profit margin of the OEM is lower under strategy PB than that under strategy NPB. That is, the introduction of contract manufacturer's private brand lowers the profit margin of the OEM. This result may be intuitive. The higher the substitution effect, the lower the profit margin. From Figure 2, when the substitution effect is sufficiently low, the advertising effort of the OEM

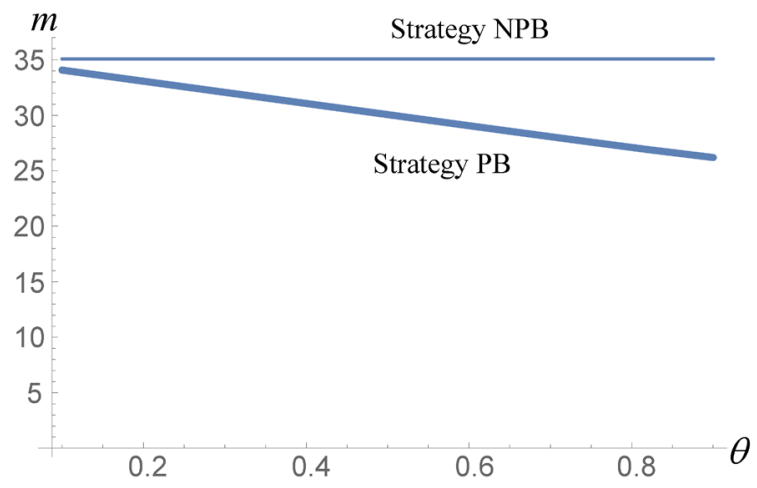

Figure 1. Profit margin of the OEM versus the substitution effect under two strategies. 


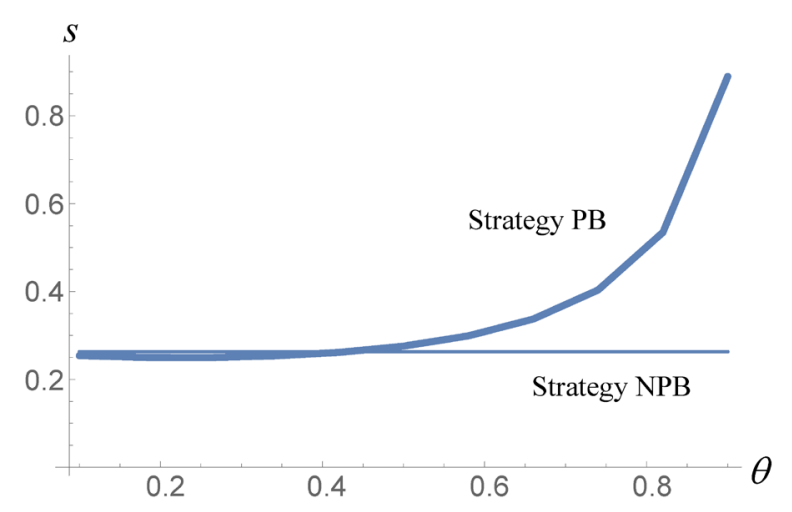

Figure 2. Advertising effort of the OEM versus the substitution effect under two strategies.

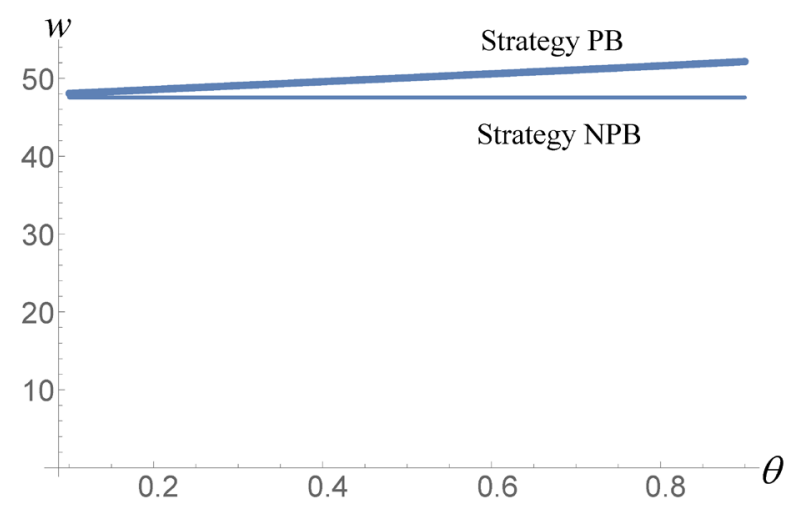

Figure 3. Wholesale price of the contract manufacturer versus the substitution effect under two strategies.

under strategy NPB is higher than that under strategy PB. However, when the substitution effect is sufficiently large, the OEM will enhance the advertising effort significantly under strategy PB. That is, the substitution effect has a great impact on the OEM's advertising effort. From Figure 3, the wholesale price of the contract manufacturer under strategy $\mathrm{PB}$ is higher than that under strategy NPB. The contract manufacturer will enhance the wholesale price when a private brand is introduced. Figure 4 shows that the profit of the contract manufacturer under strategy PB is higher than that under strategy NPB. Especially when substitution effect increases, the increase in profit is significant. Introducing a private brand is always better for the contract manufacturer when the contract manufacturer also invests on advertising effort. Figure 5 show that the introduction of the contract manufacturer's private brand is not always bad for the OEM. When the substitution effect is sufficiently high, the profit of the OEM under strategy PB is higher than that of strategy NPB. That is, introducing a private brand of the contract manufacturer will increase the profit of the OEM. Figure 6 shows that the introduction of the contract manufacturer's private brand is beneficial for the whole supply chain. Especially when the substitution effect is sufficiently high, the profit of the channel under strategy $\mathrm{PB}$ is much higher than that 


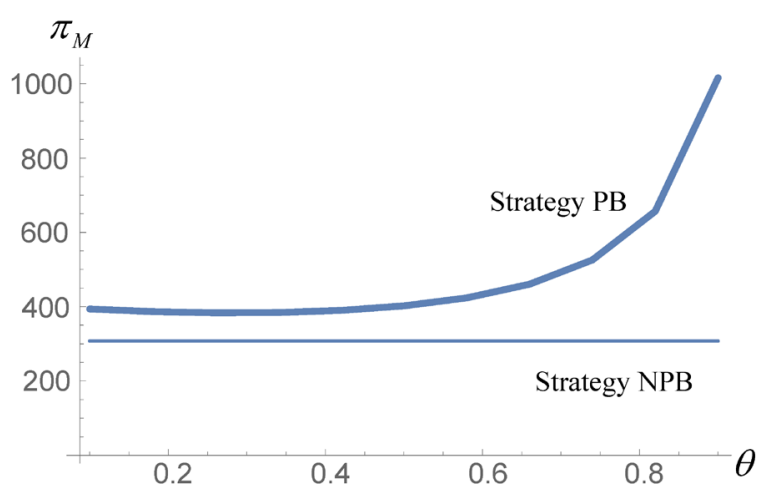

Figure 4. Profit of the contract manufacturer versus the substitution effect under two strategies.

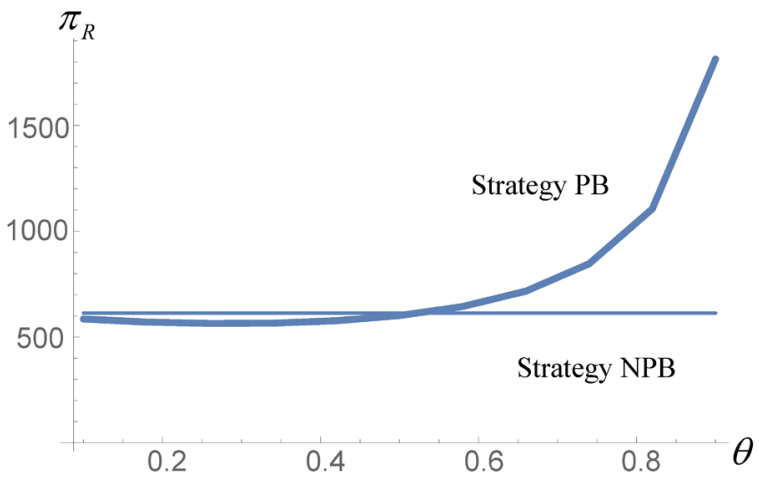

Figure 5. Profit of the OEM versus the substitution effect under two strategies.

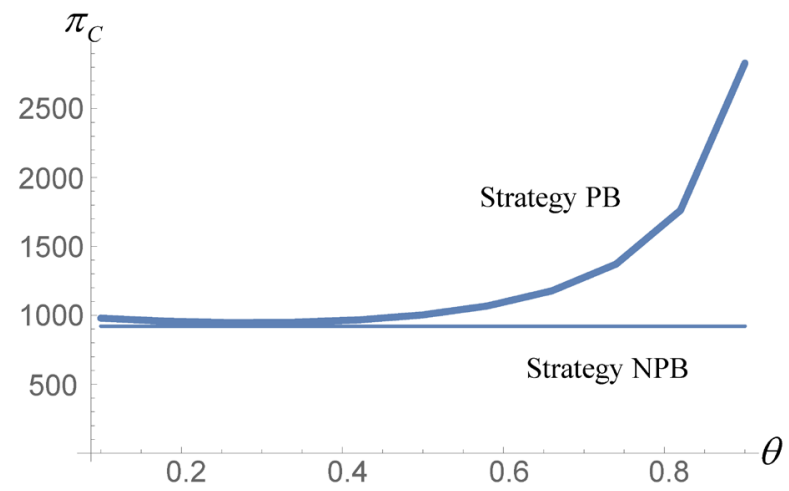

Figure 6. Profit of the whole channel versus the substitution effect under two strategies.

of strategy NPB. That is, introducing a private brand of the contract manufacturer will increase the profit of the whole channel if the substitution effect is sufficiently high.

It can be concluded that the OEM manufacturer's encroachment is bad for the OEM when the substitution effect is sufficiently low. However, when the substitution effect is sufficiently large, the contract manufacturer's encroachment is beneficial for the OEM. The result is counterintuitive because people may think that introducing a private brand by the contract manufacturer would always be 
bad for the OEM. The reason may be that when the substitution effect is sufficiently high, the introduction of the contract manufacturer's private brand will have a positive effect on the OEM's demand because the advertising effort of the private brand can enhance the demand of the OEM's brand. The encroachment of the contract manufacturer is good for the contract manufacturer and the whole channel.

\section{Conclusion}

This paper studies a supply chain consisting of a contract manufacturer and an OEM, where the contract manufacturer produces products according to the specification of the OEM. The OEM has a higher market power in the channel and moves first in the supply chain. The contract manufacturer has a chance to build her own private brand. This paper investigates the effects of the contract manufacturer's encroachment on the members of the supply chain. Firstly, the equilibriums under strategy NPB and PB are derived, respectively. Analytic results are obtained. Then numerical examples are used to illustrate the effect of the contract manufacturer's encroachment. The results show that the introduction of the private brand decreases the profit margin of the OEM and increases the wholesale price. When the substitution effect is sufficiently small, the encroachment of the contract manufacturer slightly harms the benefit of the OEM. However, when the substitution effect is sufficiently large, the encroachment of the contract manufacturer can significantly benefit the OEM. The management insight is that: For the contract manufacturer, it is better to introduce a highly substitutable brand with the OEM's brand. This can significantly benefit both the contract manufacturer and the OEM. The reason may be that the advertising effort of one brand has a positive effect on the demand of competing brand. There are certain directions for future research. Firstly, the problem can be studied in a competitive environment. Secondly, real data may be used to justify the results.

\section{Acknowledgements}

This research was supported in part by: 1) the National Natural Science Foundation of China [71601111, 71774109]. 2) Natural Science Foundation of Shanghai [18ZR1416900]. 3) Ministry of Education of Humanities and Social Science [17YJCZH054]. 4) Industrial and Informationalization Ministry of China for Cruise Program [2018-473].

\section{Conflicts of Interest}

The author declares that there is no conflict of interest regarding the publication of this paper.

\section{References}

Aust, G., \& Buscher, U. (2014). Cooperative Advertising Models in Supply Chain Man- 
agement: A Review. European Journal of Operational Research, 234, 1-14. https://doi.org/10.1016/j.ejor.2013.08.010

Berger, P. D. (1972). Vertical Cooperative Advertising Ventures. Journal of Marketing Research, 9, 309-312. https://doi.org/10.1177/002224377200900310

Berger, P. D. (1973). Statistical Analysis of Cooperative Advertising Models. Operational Research Quarterly, 24, 207-216. https://doi.org/10.1057/jors.1973.38

Berger, P. D., \& Magliozzi, T. (1992). Optimal Co-Op Advertising Decisions in Direct-Mail Operations. Journal of the Operational Research Society, 43, 1079-1086. https://doi.org/10.1057/jors.1992.165

Cai, G. G. (2010). Channel Selection and Coordination in Dual-Channel Supply Chains. Journal of Retailing, 86, 22-36. https://doi.org/10.1016/j.jretai.2009.11.002

Chaab, J., \& Rasti-Barzoki, M. (2016). Cooperative Advertising and Pricing in a Manufacturer-Retailer Supply Chain with a General Demand Function; a Game-Theoretic Approach. Computers \& Industrial Engineering, 99, 112-123. https://doi.org/10.1016/j.cie.2016.07.007

Chen, J. X., Liang, L., \& Yao, D. Q. (2019). Factory Encroachment and Channel Selection in an Outsourced Supply Chain. International Journal of Production Economics, 215, 73-83. https://doi.org/10.1016/j.ijpe.2018.05.003

Chen, J. X., Liang, L., Yao, D. Q., \& Sun, S. N. (2017). Price and Quality Decisions in Dual-Channel Supply Chains. European Journal of Operational Research, 259, 935-948. https://doi.org/10.1016/j.ejor.2016.11.016

Chen, Y. J., Shum, S., \& Xiao, W. Q. (2012). Should an OEM Retain Component Procurement When the CM Produces Competing Products? Production and Operations Management, 21, 907-922. https://doi.org/10.1111/j.1937-5956.2012.01325.x

Cui, Q. Q. (2019). Quality Investment and the Contract Manufacturer's Encroachment. European Journal of Operational Research, 279, 407-418. https://doi.org/10.1016/j.ejor.2019.06.004

De Giovanni, P. (2011). Quality Improvement vs. Advertising Support: Which Strategy Works Better for a Manufacturer? European Journal of Operational Research, 208, 119-130. https://doi.org/10.1016/j.ejor.2010.08.003

Dutta, S., Bergen, M., John, G., \& Rao, A. (1995). Variations in the Contractual Terms of Cooperative Advertising Contracts: An Empirical Investigation. Marketing Letters, 6, 15-22. https://doi.org/10.1007/BF00994036

Edirisinghe, N. C. P., \& Shi, B. B. (2011). Equilibrium Analysis of Supply Chain Structures under Power Imbalance. European Journal of Operational Research, 214, 568-578. https://doi.org/10.1016/j.ejor.2011.05.008

Fulop, C. (1988). The Role of Advertising in the Retail Marketing Mix. International Journal of Advertising, 7, 99-117. https://doi.org/10.1080/02650487.1988.11107049

Ingene, C. A., \& Parry, M. E. (2004). Mathematical Models of Distribution Channels. Berlin: Springer.

Kalra, A., \& Shi, M. (2010). Consumer Value-Maximizing Sweepstakes and Contests. Journal of Marketing Research, 47, 287-300. https://doi.org/10.1509/jmkr.47.2.287

Karray, S., \& Martín-Herrán, G. (2019). Fighting Store Brands through the Strategic Timing of Pricing and Advertising Decisions. European Journal of Operational Research, 275, 635-647. https://doi.org/10.1016/j.ejor.2018.11.066

Kaya, O. (2011). Outsourcing vs. In-House Production: A Comparison of Supply Chain Contracts with Effort Dependent Demand. Omega, 39, 168-178. https://doi.org/10.1016/j.omega.2010.06.002 
Li, S. X., Huang, Z., Zhu, J., \& Chau, P. Y. K. (2002). Cooperative Advertising, Game Theory and Manufacturer-Retailer Supply Chains. Omega, 30, 347-357. https://doi.org/10.1016/S0305-0483(02)00051-8

Niu, B. Z., Wang, Y. L., \& Guo, P. G. (2015). Equilibrium Pricing Sequence in a Cooperative Supply Chain with the ODM as a Downstream Rival of Its OEM. Omega, 57, 249-270. https://doi.org/10.1016/j.omega.2015.05.005

Ouardighi, F. E., \& Kogan, K. (2013). Dynamic Conformance and Design Quality in a Supply Chain: An Assessment of Contracts Coordinating Power. Annals of Operation Research, 211, 137-166. https://doi.org/10.1007/s10479-013-1414-4

Pan, K., Lai, K. K., Leung, S. C. H., \& Xiao, D. (2010). Revenue-Sharing versus Wholesale Price Mechanisms under Different Channel Power Structures. European Journal of Operational Research, 203, 532-538. https://doi.org/10.1016/j.ejor.2009.08.010

Shi, J. (2019). Contract Manufacturer's Encroachment Strategy and Quality Decision with Different Channel Leadership Structures. Computers \& Industrial Engineering, 137, Article ID: 106078. https://doi.org/10.1016/j.cie.2019.106078

Somers, T. M., Gupta, Y. P., \& Herriott, S. R. (1990). Analysis of Cooperative Advertising Expenditures: A Transfer-Function Modeling Approach. Journal of Advertising Research, 24, 35-45.

Song, J., Li, F., Wu, D. D., Liang, L., \& Dolgui, A. (2017). Supply Chain Coordination through Integration of Innovation Effort and Advertising Support. Applied Mathematical Modelling, 49, 108-123. https://doi.org/10.1016/j.apm.2017.04.041

Spiegel, Y. (1993). Horizontal Subcontracting. The RAND Journal of Economics, 24, 570-590. https://doi.org/10.2307/2555746

Wang, S., Zhou, Y., Min, J., \& Zhong, Y. (2011). Coordination of Cooperative Advertising Models in a One-Manufacturer Two-Retailer Supply Chain System. Computers \& Industrial Engineering, 61, 1053-1071. https://doi.org/10.1016/j.cie.2011.06.020

Xiao, Q. Z., Chen, L., Xie, M., \& Wang, C. (2020). Optimal Contract Design in Sustainable Supply Chain: Interactive Impacts of Fairness Concern and Overconfidence. Journal of the Operational Research Society. https://doi.org/10.1080/01605682.2020.1727784

Young, R. F., \& Greyser, S. A. (1983). Managing Cooperative Advertising: A Strategic Approach. Lexington, MA: Lexington Books.

Yu, N., \& Zheng, B. R. (2019). Analysis on Market Entry Strategy of ODM's Own Brand in Competitive Environment. Systems Engineering-Theory \& Practice, 39, 682-694.

Zhang, B. (2011). Optimal Policy for a Mixed Production System with Multiple OEM and OBM Products. International Journal of Production Economics, 130, 27-32. https://doi.org/10.1016/j.ijpe.2010.10.010

Zhang, C., Fang, D. L., Yang, X. T., \& Zhang, X. B. (2018). Push and Pull Strategies by Component Suppliers when OEMs Can Produce the Component In-House: The Roles of Branding in a Supply Chain. Industrial Marketing Management, 72, 99-111. https://doi.org/10.1016/j.indmarman.2018.02.012

Zhang, J., Gou, Q., Liang, L., \& Huang, Z. (2013). Supply Chain Coordination through Cooperative Advertising with Reference Price Effect. Omega, 41, 345-353.

https://doi.org/10.1016/j.omega.2012.03.009 